Pre-Print Version: Jurnal Kajian Ilmiah Universitas Bhayangkara Jakarta Raya

Vol. 9, No. 3, pp. 908-922 (2008)

ISSN 1410-9794

\title{
YURISPRUDENSI TERAPEUTIK: PERAN INTEGRATIF PSIKOLOGI DALAM PROSES HUKUM UNTUK MELAYANI KESEJAHTERAAN PRIBADI (WELL-BEING) KLIEN HUKUM
}

\author{
Juneman \\ Dosen Fakultas Psikologi Universitas Bhayangkara Jaya \& \\ Pengurus Himpunan Psikologi Indonesia Wilayah DKI Jakarta \\ E-mail: juneman@gmail.com
}

\begin{abstract}
Until recently there has been no general theory concerning the impact of legal processes upon participant wellbeing and its implications for attaining justice system objectives. This gap has been filled by therapeutic jurisprudence. Its essential premise is that the law does have therapeutic or anti-therapeutic consequences. This paper uses existing research to explore how the tools of the behavioral sciences, e.g. psychology, can be used to study the therapeutic and anti-therapeutic impact of the law, and that we can think creatively about improving the law's healing potential without violating other important values. By claiming that justice is therapy, the therapeutic jurisprudence perspective reaches beyond how to design and operate a court into a larger question of how law clients should be treated by the justice system.
\end{abstract}

Keywords: therapeutic jurisprudence, pro-therapeutic, anti-therapeutic consequences, psychological well-being, forensic psychology, pscyhology in law

\section{A. Pendahuluan}

Yurisprudensi terapeutik merupakan sebuah kerangka kerja analitis logis bagi proses hukum yang pro-terapeutik terhadap orang-orang yang berada di bawah tekanan (Wexler \& Winick, 1996; Winick, 2005). Kata "yurisprudensi" yang dimaksud dalam artikel ini merupakan terjemahan dari kata "jurisprudence", yang artinya "the science or philosophy of law" (Merriam-Webster Online Dictionary, 2008). Jadi, kata "yurisprudensi" dalam tulisan ini bukan dalam pengertian sebagaimana dimaksud Soeroso (1996), bahwa yurisprudensi adalah "keputusan hakim yang dijadikan pedoman (diikuti) oleh hakim lain dalam memutuskan kasus-kasus yang sama." Filosofi yurisprudensi terapeutik merupakan sebuah lensa yang dapat digunakan untuk meninjau dan menganalisis pengaruh-pengaruh dari hukum (Winick, 2005). Yurisprudensi terapeutik menawarkan sebuah "pendekatan lintasdisiplin terhadap pengetahuan, kerja, metode-metode hukum dan perubahan hukum yang memandang hukum itu sendiri sebagai sebuah agen terapeutik" (Winick, 2005: 6). Perspektif ilmu-ilmu keperilakuan (behavioral sciences) digabungkan dalam hal ini untuk memahami secara mendalam pengaruh hukum, untuk meminimalkan akibat-akibat yang bersifat anti-terapeutik, dan memaksimalkan potensi terapeutiknya, yakni dengan menajamkan kembali proses-proses hukum yang dapat meningkatkan keberfungsian psikologis dan kesejahteraan emosional dari orang-orang yang dipengaruhinya. Karenanya, yurisprudensi terapeutik dapat memperkuat interaksi antara para klien dan para hakim, serta meningkatkan kualitas proses pemeriksaan pengadilan dan pencarian fakta. Hal ini dapat pula mengubah persepsi negatif mengenai hukum.

Menurut Wexler (dalam University of Arizona, 2007): 
Sekolah hukum mengajarkan Anda mengenai aturan-aturan, argumen-argumen dan logika-tetapi bukan pengaruh hukum terhadap kehidupan emosional atau kesejahteraan pribadi dari orang-orang. Pengaruh-pengaruh tersebut merupakan aspek-aspek yang kurang diapresiasi oleh hukum-sebuah aspek yang telah diabaikan oleh hukum.

Melalui riset, Wexler menemukan bahwa, "Anda dapat memandang hukum sebagai sebuah kekuatan sosial dinamis dengan konsekuensi-konsekuensi dan pengaruh-pengaruh keperilakuan." Kesejahteraan pribadi (well-being) dalam konteks ini sangatlah luas, mencakup isu-isu seperti peran hukum dalam mempromosikan aktualisasi diri dari individu serta berkenaan dengan problem-problem komunitas, seperti kehancuran keluarga (Wexler \& Winick, 1996). Yurisprudensi terapeutik "berupaya untuk memfokuskan perhatian pada sebuah unsur yang seringkali diabaikan dalam perhitungan yang dibutuhkan untuk menyelenggarakan sebuah analisis kebijakan yang bijaksana bagi hukum dan praktek kesehatan mental-dimensi terapeutiknya-dan untuk menganjurkan sebuah pemeriksaan empiris sistematis terhadap dimensi ini” (Wexler \& Winick, 1991: xi).

Bruce Winick membedakan yurisprudensi terapeutik dari "model medis" (memberdayakan klinisi) dan dari perlindungan hak-hak sipil yang ditentukan oleh "model legal" (dalam hal mana hak-hak pasien dan "prosedur-prosedur" yang bagus diistimewakan). Winick (2003: 26) mengatakan:

Yurisprudensi terapeutik menganjurkan bahwa hukum hendaknya menghargai kesehatan psikologis, berjuang untuk menghindarkan konsekuensi-konsekuensi anti-terapeutik sedapat mungkin, dan apabila konsisten dengan nilai-nilai sosial lain yang dilayani oleh hukum, hendaknya berupaya untuk menciptakan penyembuhan (healing) dan kesejahteraan (wellness). Tidak seperti model medis, yurisprudensi terapeutik tidak mengistimewakan nilai-nilai terapeutik di atas yang lain, melainkan berupaya untuk memastikan apakah efek-efek anti-terapeutik dari hukum dapat dikurangi dan pengaruhpengaruh terapeutiknya ditingkatkan tanpa mensubordinasi proses-proses yang semestinya serta nilai-nilai keadilan yang lain.

Penelitian yang mula-mula terhadap yurisprudensi terapeutik menekankan hasil-hasil terapeutik bagi orang-orang dengan penyakit mental (Wexler, 1990; Wexler and Winick, 1991) dan barubaru ini telah digunakan sebagai sebuah alat analitis, atau dioperasionalkan, dalam peradilan kesehatan mental (Kondo, 2000; Slate, 2003; Steadman, Redlich, Griffin, Petrila, Monahan, 2005; Trupin \& Richards, 2003). Yurisprudensi terapeutik juga telah menjadi fondasi analisis bagi komite atau panel peradilan lain termasuk peradilan narkoba (Brown, 2001; Hora, Schma and Rosenthal, 1999; Hora, 2002) dan peradilan anak remaja (Weisz, Lott, \& Thai, 2002). Yurisprudensi terapeutik bekerjasama dengan badan-badan dan metode-metode lain dengan maksud untuk mengurangi atau meredakan stres dan trauma yang diasosiasikan dengan proses hukum, seperti keadilan restoratif yang menyembuhkan (restorative justice), peradilan perawatan klien narkoba (drug treatment courts), dan mediasi korban (victim mediation). Lebih spesifik lagi, yurisprudensi terapeutik telah pula digunakan untuk memberikan kerangka bagi penelitian terhadap "keadilan" (fairness) dari proses-proses pengadilan (Ferencz \& McGuire, 2000).

N.J. Murfett pada Konferensi Internasional Yurisprudensi Terapeutik yang ketiga (di Perth, Australia, 2006) mengilustrasikan pentingnya pergeseran paradigma dalam resolusi perselisihan sipil dan komersial, yakni bergeser atau berpindah dari ketakutan (fear) menuju cinta (love). Menurut Murfett (2006), sistem yang ada sekarang untuk menyelesaikan disputasi komersial dan sipil menghasilkan sejumlah besar disharmoni dan penderitaan emosional. Perasaan yang intens akan kemarahan, kesedihan, dan ketakutan seringkali muncul dari sistem-sistem dan proses- 
proses yang dirancang untuk menyelesaikan perselisihan tersebut. Perasaan-perasaan dan emosiemosi ini timbul dari pengalaman para partisipan-klien, pengacara, dan petugas hukum, dan emosi tersebut mungkin secara serius dinilai rendah (under estimated). Guna menjelaskan fenomena ini, ia memperlihatkan dalam tulisannya mengenai perlunya untuk memeriksa konteks fundamental atau paradigma yang mendasari sistem yang ada sekarang ini yang berbasiskan pada ketakutan (ketakutan akan kehilangan, ketakutan akan uang, ketakutan akan kegagalan, dan ketakutan kehilangan kendali atas hasil). Sistem yang ada sekarang menyelesaikan disputasi dengan permusuhan atau seringkali kombatif, namun jarang memuaskan atau menyembuhkan mereka. Nyata pula bahwa upaya-upaya untuk mereformasi tidak akan terbukti efektif sampai mereka merangkul sebuah pergeseran paradigma dari ketakutan kepada lawannya, yakni cinta. Pergeseran paradigma menuju cinta ini sejalan dengan pandangan Psikologi Positif, yang antara

lain menyatakan bahwa pencapaian kebahagiaan hendaknya menjadi kerangka kerja untuk mengukur hukum dan proses-proses yang terkait dengannya.

Menurut de Veen \& Wexler (2006), penggunaan yurisprudensi terapeutik secara yudisial memerlukan sejumlah kompetensi yang dapat dilihat sebagai sebuah kerangka kerja tripartit, yakni yang meliputi: (a) pengetahuan mengenai lanskap hukum yang relevan (sebagian besar bersifat legal); (b) pengetahuan mengenai perlakuan-perlakuan (treatments) dan jasa-jasa (services) yang relevan (sebagian besar bersifat kerja sosial, namun hakim perlu mengetahui bagaimana berbicara dengan profesi-profesi lainnya); dan (c) pengetahuan mengenai praktekpraktek yang bersumber dari teori (theory-inspired practices), yang sepenuhnya bersifat lntasdisiplin dan mencakup prinsip-prinsip "how to" yang diturunkan dari riset-riset yang relevan.

\section{B. Prinsip-prinsip Terapeutik}

Sebagaimana ilmu-ilmu keperilakuan, ilmu hukum turut mempelajari komunikasi dan modifikasi perilaku. Efektivitas hukum berakar pada kemampuan institusi-institusi dan para profesional dari sistem keadilan untuk berkomunikasi secara efektif dengan para penggugat/litigan dan dengan komunitas secara umum. Hukum dan pranatanya juga berupaya untuk memodifikasi kesejahteraan dan perilaku manusia. Dalam kasus-kasus penderitaan pribadi (personal injury), pengadilan berupaya untuk menempatkan seseorang, sedapat mungkin, dalam situasi orang tersebut sebelum penderitaan tersebut terjadi.

Riset ilmu-ilmu keperilakuan mencakup penelitian mengenai hal-hal yang efektif dan hal-hal yang kontraproduktif dalam bidang komunikasi dan modifikasi perilaku (Merry, 1984; Kenny, 1994). Yurisprudensi terapeutik berpendapat bahwa hukum dapat memperoleh manfaat dari riset ini untuk meningkatkan kualitas proses-prosesnya. Suatu bidang riset yang memiliki minat khusus terhadap hukum adalah keadilan prosedural. Peneliti dalam bidang ini telah meneliti pengalaman-pengalaman serta persepsi para litigan terhadap proses sistem keadilan (Tyler, 1996; Hunter, 2002; Warren, 2000). Oleh karena hasil dari litigasi penting bagi para penggugat, para penggugat ini juga memberikan nilai terhadap keadilan pencarian fakta (White, 1984; Wall \& Lynn, 1993; Thornton, 1993). Penggugat menghargai apabila mereka dapat menyampaikan cerita mereka terhadap sebuah pengadilan atentif dalam sebuah lingkungan yang suportif (suara), di mana mereka akan diperlakukan dengan hormat, dan cerita mereka akan dipertimbangkan dalam proses pengambilan keputusan (validasi) (Peachey, 1989). Mereka menghargai sebuah pengadilan yang memiliki etik kepedulian (ethic of care) (Merry \& Silbey, 1984). Bagi sejumlah litigan, proses menyampaikan cerita dan memperoleh validasi dari seseorang yang memiliki otoritas (seperti seorang hakim) dapat menolong untuk mempromosikan proses penyembuhan luka yang muncul dari situasi litigasi (O’Bar \& Conley, 1988; Watson, Bogart, Hutchinson, Mosher, \& Roach, 1991). 
Beberapa orang mengalami proses menceritakan sebuah peristiwa traumatis (seperti sebuah kecelakaan) sebagai hal yang lebih jauh traumatis. Orang-orang yang lain berharap menyampaikan cerita mereka, namun takut akan proses pengadilan yang akan menentang diri mereka. Memberikan lingkungan yang suportif, validasi, dan respek, tidak harus mensyaratkan suatu pengadilan. Sebagai contoh, mediasi dapat memfasilitasi penyampaian cerita terhadap pendengar yang empatis dalam setting yang tepat dan memberikan validasi bagi situasi orang tersebut sementara menolong para pihak untuk mencapai penyelesaian perselisihan (Seuffert, 1996).

Hukum dan proses-prosesnya pada akhirnya didukung oleh penggunaan kekuatan (Mnookin \& Kornhauser, 1979). Kendati demikian, yurisprudensi terapeutik menyoroti secara kritis pengaruhpengaruh anti-terapeutik dari penggunaan koersi dan proses-proses paternalistik. Yurisprudensi terapeutik menekankan pentingnya kontrol seseorang atas apa yang terjadi pada dirinya, sehingga orang tersebut mampu memilih apa yang dilakukannya. Dengan perkataan lain, yurisprudensi terapeutik menekankan nilai determinasi diri (self-determination) dalam mempromosikan kesehatan.

Determinasi diri merupakan sebuah nilai yang diakui dalam sejumlah konteks. Nilai ini dipandang penting bagi kesehatan dan kesejahteraan kolektif. Winick menyatakan bahwa otonomi, kemampuan untuk memilih, merupakan basis bagi teori-teori etis, seperti utilitarianisme Bentham dan Mill dan teori-teori dari Kant dan Rawls. Kendati pada sejumlah konteks, hukum membatasi atau meniadakan hak untuk memilih, seperti dalam penjatuhan sanksi-sanksi kriminal, namun dalam kaitannya dengan kesehatan, Winick (1991) menjelaskan pentingnya pilihan, sebagai berikut:

Psikologi sosial dan psikologi kognitif memberikan penjelasan teoritis, seperti alasan mengapa membolehkan pilihan individual meningkatkan potensi sukses. Orang yang diarahkan untuk mengerjakan suatu tugas tidak merasa secara personal komit terhadap tujuan atau secara personal bertanggungjawab atas pemenuhan tugas tersebut. Perasaan ini berlaku bahkan bagi tugas-tugas yang diarahkan untuk menunjukkan kinerja untuk pendorongan minat-minat terbaiknya sendiri, seperti dalam pengobatan medis. Di sisi yang lain, pilihan (choice) memberikan suatu derajat komitmen yang memobilisasikan mekanisme yang bersifat evaluasi diri (self-evaluative) dan penguatan diri (selfreinforcing) yang memfasilitasi pencapaian tujuan.

Dalam peristilahan proses hukum, dalam kaitannya dengan klaim penderitaan pribadi, pengacara dapat mempromosikan determinasi diri kliennya dengan mengikutkan mereka dalam proses pengambilan keputusan. Sudah barang tentu, keputusan klien lah yang akan menentukan apakah prosiding dilembagakan, didiskontinu, diselesaikan, atau diproses ke pemeriksaan pengadilan. Namun, strategi-strategi dengan mana prosiding dilakukan ditentukan secara umum oleh para pengacara mereka. Winick menyarankan bahwa seorang pengacara dapat mempromosikan determinasi diri dan rasa kontrol proses dari klien dengan mengikutkan klien dalam formulasi strategi yang mencakup tingkah laku dalam pemeriksaan pengadilan (Winick, 1991). Hal ini dapat menolong untuk mengurangi sifat penuh tekanan (stressful) dari prosiding-prosiding semacam itu. Sementara pada satu sisi pengacara memiliki pengalaman dan kebijaksanaan dalam ruang pengadilan dalam kaitannya dalam penentuan strategi dalam prosiding pengadilan, pada sisi yang lain klien memiliki minat akan bagaimana kasus mereka diperlakukan, bagaimana cerita mereka dipresentasikan kepada pengadilan, dan akan hasil dari prosiding; suatu minat yang erat berkaitan dengan kesejahteraan pribadi mereka. Seorang pengacara yang sensitif terhadap kesejahteraan pribadi kliennya dapat mengikutkan kliennya dalam strategi proses pengambilan keputusan dengan memberikan mereka hak suara, validasi, dan respek tanpa harus 
mengkompromikan proses hukum klien di pengadilan. Winick memberikan pembahasanpembahasan yang lebih ekstensif, seperti sarana-sarana atau alat-alat lain yang dapat dipakai konselor pengadilan yang dapat mempromosikan pengurangan pengaruh-pengaruh yang penuh tekanan dari litigasi terhadap diri klien.

\section{Sejarah Yurisprudensi Terapeutik}

Yurisprudensi terapeutik tumbuh dari karya-karya hukum kesehatan mental dari Profesor David Wexler (dari University of Arizona Rogers College of Law dan University of Puerto Rico School of Law) dan Profesor Bruce Winick (dari University of Miami School of Law). Pada akhir tahun 1980-an, mereka menamai pendekatan mereka sebagai "yurisprudensi terapeutik", dan menulis sejumlah buku serta artikel yang mendefinisikan pendekatan tersebut serta mengilustrasikan penerapannya dalam wilayah hukum kesehatan mental, di antaranya Essays in Therapeutic Jurisprudence (Wexler \& Winick, 1991). Meskipun dimulai dari hukum kesehatan mental, bidang ini segera berkembang dengan memberikan perhatian pada bidang-bidang hukum lain, yang merentang dari hukum kriminal., hukum keluarga, hukum anak-anak, dan hukum kesehatan, sampai dengan hukum kontrak dan komersial, hukum kerugian, hukum pembuktian, dan profesi legal; bahkan, akhir-akhir ini, melintasi spektrum legal karena "perkawinan" antara ilmu hukum dengan psikologi serta disiplin lain, seperti keadilan kriminal (criminal justice), kesehatan publik (public health), kerja sosial (social work), filsafat, psikiatri, dan antropologi. Sebuah ikhtisar dari kerja-kerja yurisprudensi terapeutik dalam area-area ini dan area-area hukum lain serta komentarkomentar terhadap pendekatan ini dipublikasikan dalam buku Wexler \& Winick (1996), Law in a Therapeutic Key: Developments in Therapeutic Jurisprudence. Pada tahun 2000, Wexler \& Winick (bersama dengan pengacara/psikolog Dennis Stolle) mempublikasikan buku yang mereka sunting bersama, Practicing Therapeutic Jurisprudence: Law As A Helping Profession (pengaplikasian paradigma yurisprudensi terapeutik terhadap proses penasihatan hukum). Pada tahun 2003, Winick \& Wexler mempublikasikan Judging in a Therapeutic Key: Therapeutic Jurisprudence and the Courts, dan sebuah buku suntingan yang memeriksa perkembanganperkembangan terakhir mengenai sesuatu yang diistilahkan sebagai "peradilan pemecahanmasalah" (problem-solving courts, atau collaborative-justice courts), serta menawarkan yurisprudensi terapeutik sebagai sebuah dasar teoritis bagi model-model yudisial yang baru ini dan sebuah sumber petunjuk-petunjuk instrumental mengenai bagaimana para hakim yang melayani dalam peradilan ini dapat memainkan peran mereka secara lebih efektif. Winick juga mempublikasikan karya yang ditulisnya sendiri mengenai yurisprudensi terapeutik, Civil Commitment: A Therapeutic Jurisprudence Model pada tahun 2005, di samping buku-bukunya yang lain Therapeutic Jurisprudence Applied: Essays on Mental Health Law (Carolina Academic Press, 1997) dan The Right to Refuse Mental Health Treatment (American Psychological Association Books, 1997), serta buku yang disunting bersama John Lafond, Protecting Society from Sexually Dangerous Offenders: Law, Justice, and Therapy (American Psychological Association Books, 2003). Winick \& Wexler juga seringkali menjadi pembicara pada pertemuanpertemuan asosiasi-asosiasi profesi lain dan pada sekolah-sekolah hukum, kedokteran, dan konferensi-konferensi dan program-program departemen psikologi.

Di samping mempelajari dan berupaya mereformasi aturan-aturan legal substantif dan prosedurprosedur legal, yurisprudensi terapeutik memfokuskan perhatian pada bagaimana hukum diterapkan oleh pelaku-pelaku hukum yang beragam, seperti hakim, pengacara, polisi, dan saksi ahli yang membantu pengadilan. Dalam tahun-tahun belakangan ini, terdapat perkembangan minat dalam aplikasi yurisprudensi terapeutik terhadap proses mengadili (judging) dan menasihati (lawyering). Yurisprudensi terapeutik juga telah memberikan manfaat bagi korban, narapidana, pekerja sosial, dan orang lain, yang berminat mempromosikan rehabilitasi dan meningkatkan kesejahteraan dan kepuasan emosional 
Winick \& Wexler telah beberapa kali menjadi pembicara kunci pada berbagai konferensikonferensi yudisial, termasuk American Judges Association, National Association of Women Judges, dan konferensi-konferensi lainnya. Winick sendiri berbicara pada Pertemuan Tahunan American Bar Association Appellate Judges' Section, dan National Association of Drug Court Professionals, serta di Fordham Law School (February, 2002, dengan tema "Problem-solving Courts").

Yurisprudensi terapeutik telah menjadi subjek publikasi isu spesial dari jurnal American Judges Association, "Court Review". Winick \& Wexler mempublikasikan terbitan simposium, sebagai tambahan atas bukunya Practicing Therapeutic Jurisprudence: Law as a Helping Profession (2000) bersama Profesor Edward Dauer, mengenai integrasi yurisprudensi terapeutik dengan hukum pencegahan (preventive law)-lihatlah: Therapeutic Jurisprudence and Preventive Law: Transforming Legal Practice and Education, Psychology, Public Policy \& Law, 793-1210 (1999). Yurisprudensi terapeutik menjadi kerangka kerja pengorganisir sebuah buku internasional yang dipublikasikan baru-baru ini, Involuntary Detention and Therapeutic Jurisprudence: International Perspectives on Civil Commitment (Kate Diesfeld \& Ian Freckleton, Eds., 2003). Konferensi internasional yang khusus membahas yurisprudensi terapeutik telah diselenggarakan tiga kali, yakni di Winchester, Inggris (Juli, 1998), Sekolah Hukum Universitas Cincinnati (Mei, 2001), dan Perth, Australia (Juni, 2006). Yurisprudensi terapeutik telah menjadi subjek dari pertemuan-pertemuan berskala nasional maupun internasional, seperti International Association of Law and Mental Health, European Association of Psychology and Law, Australian and New Zealand Association of Psychiatry and Psychology, American Psychology-Law Society, dan sebagainya..

\section{Contoh Upaya yang Telah Dilakukan di Dunia}

Pada tahun 2005, Goldberg \& Dimond menulis sebuah artikel dalam jurnal Clinical Child Psychology and Psychiatry dengan judul "Can Adolescent Court Reports be Used to Facilitate Therapeutic Change?" Dalam artikel itu, mereka mengajukan proposal mengenai bagaimana laporan yang disusun untuk pengadilan kriminal dapat bermanfaat bagi orang-orang muda yang diajukan ke muka pengadilan. Tujuan utama dari laporan psikiatris yang dibuat untuk pengadilan adalah guna menjawab pertanyaan-pertanyaan yang diajukan oleh dan/atau untuk pengadilan tersebut. Dalam tulisannya, Goldberg \& Dimond berpendapat bahwa proses mempersiapkan dan menuliskan laporan pengadilan remaja (adolescent court report) dapat pula digunakan untuk mempromosikan perubahan. Mereka menggambarkan bagaimana laporan psikiatris remaja yang dipersiapkan untuk prosiding pengadilan kriminal dapat digunakan untuk mendorong perubahan terapeutik bagi sang remaja, sementara agenda pengadilan tetap berjalan. Serangkaian tahap telah disarankan untuk memfasilitasi perubahan terapeutik melalui proses preparasi dan penulisan laporan yang dimaksud. Sejumlah pendekatan terapeutik yang dijadikan perspektif teoritis dalam hal ini, sebagai berikut: (a) alliance-building interventions, termasuk di dalamnya cognitive developmental approach; (b) structural family therapy; dan (c) crisis theory.

Alliance-building interventions menjelaskan bagaimana membangun aliansi dan keterlibatan kolaboratif sang remaja dalam menyusun sebuah laporan yang ditujukan untuk menjawab pertanyaan pengadilan. Perspektif ini mengandaikan bahwa sang remaja memiliki kebutuhan untuk berubah, memiliki pemikiran mengenai hal-hal yang menyebabkan masalah yang terjadi serta mengenai hal-hal yang tengah menghalangi solusi yang diinginkan. Dalam hal ini, sebuah wawancara motivasional dapat digunakan sebagai sarana untuk mengubah perilaku. Dalam perspektif structural family therapy, permintaan laporan pengadilan berpeluang untuk menginvestasikan otoritas (meskipun sementara) ke dalam diri profesi kesehatan mental yang 
ditugaskan pengadilan untuk membuat laporan, sehingga dapat meningkatkan keterlibatan dari klien atau keluarganya, bahkan yang enggan terlibat. Melalui sejumlah penelitian, ditemukan bahwa para remaja seringkali berespons secara baik terhadap hadirnya otoritas apabila mereka mengerti bahwa hal tersebut dapat menguntungkan diri sang remaja itu sendiri dalam jangka panjang. Crisis theory berpandangan bahwa momen-momen krisis dapat membuka "jendela kemungkinan" bagi perubahan dan diskusi-diskusi untuk kepentingan masa depan.

Berikut ini adalah contoh 5 (lima) langkah yang diusulkan Goldberg \& Dimond (2005) dalam rangka persiapan penyusunan laporan pengadilan bagi seorang klien remaja:

- Langkah pertama: Mengklarifikasikan (membuat menjadi sejelas mungkin) pertanyaan-pertanyaan yang diajukan oleh dan/atau untuk pengadilan. Pertanyanpertanyaan yang diajukan hendaknya dimengerti dengan jelas oleh baik klien hukum itu sendiri, keluarganya, maupun suporter klien. Metode untuk klarifikasi ini antara lain dengan cara mengulangi pertanyaan, membahasakan ulang (parafrase) pertanyaan dalam bahasa sehari-hari, sampai dimengerti/diterima oleh para pihak yang terlibat dalam proses hukum.

- Langkah kedua: Mengupayakan keterlibatan (engangement) dari pihak-pihak yang berkepentingan. Klien perlu dimotivasi untuk setuju untuk melibatkan partisipasi orangtua, keluarga, atau pendampingnya, atau bahkan keluarga besar lain, meskipun terdapat problem parental di masa lalu. Klien juga perlu dijelaskan bahwa kadang-kadang asesmen individual diperlukan dala proses-proses lebih lanjut. Pengalaman Goldberg \& Dimond menunjukkan bahwa keterlibatan ayah klien dapat mendorong terjadinya perubahan, khususnya sewaktu terjadi perdebatan antara ayah dan anaknya (klien) mengenai masa depan klien, kendatipun sang ayah barangkali tidak berperan sebagai ayah yang baik pada masa lalu kehidupan klien.

- Langkah ketiga: Menegosiasikan target-target perubahan. Pertanyaan-pertanyaan utama dalam hal ini adalah, "Apakah klien dan orangtuanya menginginkan sesuatu perubahan, dan apabila iya, perubahan seperti apakah itu? Bagaimanakah mempersiapkan klien untuk survive dalam prosiding pengadilan dan menghadapi konsekuensi-konsekuensi yang mungkin terjadi? Bagaimanakah klien dapat keluar dari lingkar aktivitas kriminal atau pun penyimpangan perilakunya? Apakah yang dikehendaki klien dan orangtuanya bagi masa depan klien? Bagaimanakah caranya agar klien tidak lagi jatuh dalam situasi yang serupa?" Supaya pertanyaan-pertanyaan tersebut dapat dijawab, perlu dilihat urgensi dalam memunculkan perasaan "sungguh-sungguh butuh jawaban" (desperation), sehingga proses penemuan dan pengelaborasian pilihan-pilihan jawaban merupakan suatu proses yang menantang untuk mengupayakan perbaikan situasi yang sudah terjadi atau menghadapi masa depan yang masih harus dijalani.

- Langkah keempat: Merancang serangkaian pertemuan untuk menjawab pertanyaan yang diajukan oleh dan/atau untuk pengadilan dan untuk menetapkan hal-hal yang perlu diupayakan bagi agar terjadi perubahan yang diinginkan klien. Rangkaian pertemuan ini memiliki dua tujuan. Tujuan pertama, untuk mengumpulkan informasi yang relevan sambil mencari pola-pola, ambiguitas, dan perbedaan-perbedaan yang ada diantara pihak-pihak yang terlibat tadi. Dalam hal ini, mungkin terjadi perdebatan yang bermanfaat untuk menyelesaikan persoalan yang sebelumnya tidak terselesaikan (to finish unfinished business) antara klien (sang remaja) dengan orangtuanya. Tujuan kedua, untuk menyadarkan orangtua/pendamping klien bahwa klien perlu berubah dengan rencana perubahan dan cara berubahnya sendiri, sehingga perubahan itu menjadi mungkin bagi klien; jadi bukan perubahan yang dipesankan/dipaksakan oleh keluarga (proses ini mungkin dirasakan sulit, berat, dan menyiksa bagi keluarga)-yang dapat dipandang tidak mungkin oleh klien. Selanjutnya, proses ini melibatkan baik terapi individual maupun terapi keluarga. Penggunaan formula, "ketika waktunya tepat", dapat membuat perubahan masa depan 
menjadi lebih dapat dinegosiasikan. Dalam hal ini, brainstorming mengenai kondisi-kondisi yang dapat dipilih klien untuk menginisiasikan suatu perubahan dapat dengan sendirinya menawarkan harapan kepada klien.

- Langkah kelima: Menjawab pertanyaan yang diajukan oleh dan/atau untuk pengadilan dengan cara tertentu sedemikian rupa sehingga laporan yang disusun mencakup rencana untuk melembagakan perubahan yang telah disetujui. Apapun tujuan terapeutiknya, laporan pengadilan harus ditulis untuk menjawab pertanyaan-pertanyaan yang diajukan oleh dan/atau untuk pengadilan. Untuk memastikan hal ini, laporan dapat distrukturkan berdasarkan pertanyaan-pertanyaan yang telah disepakati dengan mengulanginya dalam pendahuluan laporan dan menjawabnya dalam suatu sekuens (urutan) jawaban di dalam kesimpulan. Sebagai bagian dari jawaban atas pertanyaan-pertanyaan tersebut, informasi yang diperoleh dari upaya untuk mendesak perubahan terapeutik dapat dimasukkan. Sebagai contoh, pemasukan care plan yang telah dinegosiasikan bersama klien dapat diikutsertakan menjadi informasi bagi pengadilan. Klien dan pendamping klien dapat diberikan kesempatan untuk membaca draf laporan, untuk mengkoreksi kekeliruankekeliruan faktual, dan untuk menanyakan pertanyaan-pertanyaan mengenai bagaimana profesi kesehatan mental [psikolog/psikiater/dll] dapat mencapai suatu kesimpulan tertentu. Pada umumnya, opini profesi kesehatan mental tidak mengejutkan klien dan keluarganya karena memang telah diekspresikan dan dikembangkan dalam pertemuan-pertemuan sebelumnya. Bekerjasama untuk mengasimilasikan umpan balik masing-masing pihak adalah penting bagi keberlanjutan kolaborasi antara klien dan profesi kesehatan mental. Sebagai bagian dari proses ini, dapat diadakan diskusi mengenai apakah dirasakan berguna untuk merekomendasikan rencana manajemen yang disepakati bersama sebagai bagian dari supervisi komunitas. Hal ini dapat dilihat dalam kerangka pandang yang positif, dalam hal mana dapat menjadi faktor motivasional bagi klien, serta untuk memastikan bahwa perubahan yang diinginkan klien terjadi secara aktual dalam praktek di lapangan.

\section{E. Yurisprudensi Terapeutik bagi Proses Hukum di Indonesia}

Sebagaimana disebutkan pada awal tulisan ini, yurisprudensi terapeutik menggunakan perspektif ilmu-ilmu keperilakuan, seperti ilmu psikologi, untuk menajamkan proses-proses hukum sedemikian sehingga dapat meningkatkan keberfungsian psikologis dan kesejahteraan emosional dari orang-orang yang dipengaruhi oleh hukum. Bila kita mengikuti definisi The Committee on Ethical Guidelines for Forensic Psychology (dalam Asosiasi Psikologi Forensik Indonesia, 2008) terhadap istilah "psikologi forensik" sebagai "semua bentuk layanan psikologi yang dilakukan di dalam hukum.", maka yurisprudensi terapeutik dapat digolongkan sebagai salah satu bidang kajian psikologi forensik.

Dalam kaitan dengan psikologi forensik, Adrianus Meliala (2008) menyebutkan empat (kemungkinan) bentuk kontribusi psikologi forensik, khususnya dalam praktek beracara di persidangan (sebagai entry-point psikolog masuk dalam dunia hukum), sebagai berikut: (a) sebagai saksi ahli; (b) sebagai pemberi nasihat ahli di luar persidangan untuk hal-hal yang terkait dengan persidangan pada umumnya (berupa opini atau pun hasil penelitian), baik kepada hakim/badan peradilan umumnya, tersangka/perwakilannya, dan korban/perwakilannya; (c) sebagai hakim ad-hoc; dan (d) sebagai pendidik para calon hakim atau pemberi penyegaran pada hakim senior (dalam tiga fokus, yakni: situasi psikologis hakim sebagai manusia biasa saat menyidangkan perkara, proses persidangan itu sendiri sebagai suatu teater psikologis, dan saat pengambilan keputusan pidana). Wrightsman \& Solomo (dalam Poerwandari, 2006) menyebutkan pula bentuk kontribusi psikologi forensik dalam peristilahan yang lain, yakni: (a) sebagai konsultan bagi penegak hukum; (b) sebagai konsultan peradilan; (c) sebagai evaluator forensik dan/atau saksi ahli; (d) sebagai saksi ahli, yang bukan hanya bersaksi tentang fakta 
objektif, melainkan juga dapat menyampaikan pendapat karena dianggap memiliki keahlian khusus; dan (e) sebagai teman peradilan pemberi informasi ilmiah (amicus curiae briefs). Lebih lanjut, Poerwandari (2006) menyatakan bahwa psikologi menjadi bagian yang sangat penting dalam penanganan terintegrasi seorang klien hukum, mulai dari dimensi penanganan krisis-medis, medis lanjutan, jaminan keselamatan, pemenuhan kebutuhan dasar, pendampingan psikologis, penguatan ekonomi, penanganan hukum, sosialisasi nilai, advokasi kebijakan, sampai dengan dimensi pengembangan etika, moralitas, dan spiritualitas baru. Yusti Probowati (2008) memaparkan dua buah teknik investigasi perkara yang menggunakan prinsip psikologi, yaitu teknik hipnosis dan wawancara kognitif, yang bertujuan untuk mencari kebenaran kesaksian.

Kesejahteraan psikologis ternyata senantiasa mendapat perhatian, baik pada diri hakim (Meliala, 2008), saksi dan/atau korban (Probowati, 2008), maupun pelaku kejahatan (Poerwandari, 2006). Namun demikian, Poerwandari (2006) mengingatkan bahwa penanganan psikologis pada pelaku kejahatan hanya dapat efektif dilakukan pada orang yang memiliki insight (kesadaran) bahwa ia melakukan kesalahan; dan, bila tidak hati-hati, hal ini dapat dimanfaatkan oleh pelaku untuk menghindar dari sanksi hukum. Maka, pelaku perlu difasilitasi untuk mampu berempati terhadap situasi korban serta merekonstruksi pemahaman atas peristiwa kriminal yang ia lakukan.

Daicoff \& Wexler (2003) mengkaji aplikasi yurisprudensi terapeutik dalam penasihatan terapeutik atau therapeutic lawyering (yakni dalam hal-hal: litigasi, integrasi dengan hukum pencegahan, dan psycholegal soft spots, serta penekanannya pada relasi dan pengembangan manusia), dan penerapan spesifik pada hukum kriminal, hukum personal injury, hukum pekerjaan, dan hukum keluarga.

Yang perlu mendapat perhatian adalah pertanyaan, "Terhadap siapa upaya terapeutik perlu diupayakan?" ("Therapeutic for whom?") (Slobogin, 1995). Proposisi Slobogin adalah bahwa suatu yurisprudensi mungkin terapeutik bagi satu atau sejumlah orang/pihak namun sekaligus berpotensi anti-terapeutik bagi orang/pihak yang lain. Situasi dilematis semacam ini seringkali muncul dari bidang hukum yang terkait dengan hubungan, atau "hukum relasi" (relationship law), termasuk hukum kontrak, hukum keluarga, hukum pekerjaan, hukum partnership, hukum kepercayaan dalam pengaturan keuangan, dan sebagainya.

Sebagai contoh hal di atas adalah hukum pengasuhan anak yang orangtuanya bercerai (child custody law). Dewasa ini, kasus-kasus seperti ini banyak kita jumpai pada kalangan selebriti Indonesia. Dalam persidangan yang membahas hak pengasuhan anak, pengacara tradisional cenderung untuk berfokus pada permintaan klien (suami-istri yang bercerai). Permintaan ini dapat cocok atau tidak cocok dalam hal pengaruh terapeutik yang terbaik bagi anak. Misalnya, kedua orangtuanya mungkin menginginkan joint custody, di mana si anak dapat diasuh oleh baik suami atau istri, namun pengaturan semacam itu dapat bersifat anti-terapeutik bagi si anak, oleh karena instabilitas kondisi pengaturan (memiliki dua rumah/two homes). Meskipun demikian, dalam kasus-kasus yang lain, sebuah tindakan hukum dapat bersifat terapeutik bagi seluruh individu yang terlibat. Misalnya, apabila terdapat kekerasan suami terhadap istri atau istri terhadap suami, maka mengupayakan agar suami/istri yang melakukan kekerasan dipisahkan dari rumah, pasangan, dan anak-anaknya, dapat merupakan aksi terapeutik baik bagi suami/istri (utamanya yang menjadi korban kekerasan) maupun anak-anaknya.

Apabila Adrianus Meliasa (2008) menyatakan bahwa masih terbatas aplikasi psikologi forensik terkait dunia peradilan, namun pada saat yang sama juga terdapat prospek untuk meningkat; maka dapat dilihat bahwa aplikasi yurisprudensi terapeutik sebagai salah satu saja dari bidang kajian psikologi forensik jauh lebih terbatas, khususnya di Indonesia. Namun, dengan mengingat signifikansi peran yurisprudensi terapeutik, sebagaimana terungkap dalam seluruh uraian di atas, 
maka usaha dari para ilmuwan dan profesi psikologi maupun hukum di Indonesia dalam kajian dan penerapan yurisprudensi terapeutik menjadi nampak urgensinya. Sebagai contoh dari hal ini adalah bagaimana agar istilah "shock therapy" dimaknai secara lebih tepat. Misalnya, ada pengamat yang menggunakan istilah tersebut, dalam berita "Baju Khusus Koruptor Pas untuk Shock Therapy" (DetikNews DetikCom, Agustus 2008) sebagai berikut, "Baju khusus untuk koruptor diharapkan dapat menjadi shock therapy dan dapat menimbulkan superioritas bagi penyidik KPK saat berhadapan dengan sang koruptor." Dalam kaitannya dengan pandangan yurisprudensi terapeutik, maka shock therapy hendaknya tidak perlu hanya berkonotasi "balas dendam" (bagi penonton), atau sekadar "membuat kapok (jera) pelaku", melainkan juga berkonotasi lebih positif dan prospektif-karena terapi ini dimaksudkan untuk menyembuhkan dan bukan menyakiti, yakni adanya upaya penyusunan dan penerapan strategi terapeutik agar pelaku menyadari perbuatan serta mampu merencanakan, melakukan tindakan perbaikan diri sendiri secara luas (tidak hanya menyangkut persoalan kejahatan korupsi), dan hal ini mampu bertahan dalam jangka panjang; atau dalam istilah Poerwandari (2006) di atas, hal ini termasuk dalam dimensi penanganan psikologis "pengembangan etika, moral, dan spiritualitas baru". Bagi pengacara, pendekatan terhadap klien dapat diubah dari sekadar menyuruh klien "melakukan ini", "menjawab ini", atau "tidak melakukan atau menjawab itu"(dan setelah itu selesai, menang/kalah secara legal di pengadilan)" menuju ke pembukaan keterlibatan aktif klien demi memperhatikan kesejahteraan psikologis pribadinya sendiri.

\section{F. Perdebatan Seputar Yurisprudensi Terapeutik}

Beberapa kritik telah diajukan mengenai penerapan yang luas dari prinsip-prinsip terapeutik terhadap prosiding-prosiding hukum (Nolan, 2000; Arrigo, 2004) dan secara lebih khusus penerapannya pada hukum kesehatan mental (Petrila, 1996; Eastman \& Peay, 1999). Sebagai contoh, Petrila (1996) mempertanyakan apakah tujuan-tujuan terapeutik seyogianya memainkan peran yang dominan dalam pengambilan keputusan yudisial. Secara potensial, yurisprudensi terapeutik dapat memperluas pengaruh yudisial atas pengambilan keputusan klinis dengan konsekuensi pengurangan otonomi para pengguna layanan hukum. Petrila (1996: 688) juga menekankan bahwa seseorang harus menanyakan "siapa yang memutuskan" hal-hal yang merepresentasikan hasil terapeutik, dan mencatat bahwa para pengguna layanan hukum mungkin "sangat tidak setuju" dengan premis bahwa hukum hendaknya mengupayakan hasil-hasil terapeutik. Petrila menyatakan bahwa pendekatan terapeutik mungkin saja bersifat konservatif, atau bahkan paternalistik, khususnya dalam kondisi apabila "orang-orang yang dapat memberikan informasi terbaiknya mengenai hasil-hasil terapeutik dari intervensi legal atau terapeutik dikucilkan partisipasinya dalam proses analisis yang justru memerlukan keikutsertaan mereka."

Lebih luas lagi, Nolan (1998) mempertanyakan lebih jauh apakah yurisprudeni terapeutik akan memperluas cakupan otoritas medis dengan penyamaran berbentuk intervensi yang bijak dan terapeutik dengan konsekuensi pelanggaran kebebasan individual. Beberapa pengritik lain, misalnya Eastman \& Peay (1999), mengidentifikasikan sebuah konflik filosofis yang mendasar dalam konsep yurisprudensi terapeutik:

Argumen belakangan ini, yang direpresentasikan dengan gerakan "yurisprudensi terapeutik", bahwa semua hukum hendaknya dirancang demi manfaat terapeutik secara jelas mengimplikasikan bahwa hukum kesehatan mental seyogianya dilihat sebagai setara dengan sebuah alat klinis. Pandangan yang bertentangan, yang direpresentasikan oleh pengacara ketimbang klinisi, ialah bahwa meskipun hukum kesehatan mental orangorang Inggris dan Wales sungguh-sungguh memiliki tujuan terapeutik, sebagian besarnya secara tepat memperhatikan hak-hak sipil akan proteksi pasien terhadap terapi yang tidak 
beralasan serta perlindungan terhadap kebebasan sipil mereka. Penyandingan kedua pendekatan ini dalam hukum kesehatan mental menggambarkan sebuah ketegangan kebijakan publik di lapangan, antara pencapaian kesejahteraan paternalistik dan keadilan yang berasal dari otonomi.

Penelitian-penelitian lintasdisiplin mengenai maksud dan fungsi dari yurisprudensi terapeutik dapat membantu untuk mengevaluasi pengaruh dari intensi-intensi terapeutik, praktek-praktek anti-terapeutik, dan perspektif-perspektif baru dari literatur yurisprudensi terapeutik. Sebagai contoh, Diselfeld \& McKenna (2006) menemukan di Selandia Baru, dalam penelitiannya pada tahun 2003 sampai dengan 2004, bahwa keputusan-keputusan pengadilan di negara tersebut menunjukkan penegakkannya terhadap misi terapeutik. Meskipun demikian, sejumlah faktor perlu diperhatikan dalam rangka menganalisis penerapan dari prinsip-prinsip terapeutik yang bermaksud memberikan manfaat bagi para pengguna layanan hukum. Faktor-faktor tersebut misalnya pengaruh dari intensi pro-terapeutik dari badan-badan hukum dalam proses advokasi, pengambilan keputusan klinis, dan pelaksanaan prosiding. Studi-studi yang tengah berkembang mengenai yurisprudensi terapeutik dapat menawarkan dasar-dasar analitis yang relevan.

Penelitian lebih lanjut mungkin akan bermanfaat bila dilakukan pemeriksaan lebih jauh mengenai interpretasi dari kata "terapeutik", antara lain oleh pengguna layanan hukum (Petrila, 1996, Ferencz, 2003), pengacara (Delaney, 2003), dan para anggota badan peradilan (Du Fresne, 2003). Pengguna layanan hukum memerlukan pandangan yang jelas apakah prosiding-prosiding hukum yang mereka jalani adalah adil dan terapeutik.

\section{G. Kesimpulan dan Rekomendasi}

Yurisprudensi terapeutik merupakan sebuah perspektif yang menawarkan proses dialogis antara para hamba hukum dan para klien hukum, yang menggunakan prinsip-prinsip psikologi yang diintegrasikan dengan proses hukum. Perspektif ini, sebagaimana telah ditunjukkan dalam uraian di atas, memberikan cara pandang yang lebih kreatif dan fleksibel terhadap proses hukum, meskipun sejumlah faktor masih harus sungguh-sungguh diperhatikan agar intensi pro-terapeutik tidak malah berbalik menjadi anti-terapeutik. Tingkat akseptansi klien hukum terhadap suatu keputusan hukum dapat menjadi lebih tinggi apabila pengadilan berinteraksi dengan mereka dengan cara tertentu yang lebih bijak dan memperhatikan kepentingan keberfungsian psikologis, kesehataan emosional, dan kesejahteraan psikologis umum mereka. Pun terdapat sejumlah bukti pengalaman empiris bahwa para pengacara akan memperoleh respek yang lebih dari klien mereka apabila mereka menunjukkan perhatian (care), yang bila dianalogikan, seperti cara seorang dokter berbicara dengan pasien yang sedang dirawatnya. Dalam bahasa Inggris, hal ini diterminologikan sebagai “bedside manner" (Wexler dalam University of Arizona, 2007).

Gagasan-gagasan yurisprudensi terapeutik yang disajikan dalam artikel ini merupakan suatu posibilitas yang perlu terus-menerus diupayakan aplikasinya secara luas di Indonesia. Untuk itu, organisasi profesi psikologi Himpsi (Himpunan Psikologi Indonesia), khususnya Asosiasi Psikologi Forensik Indonesia (Apsifor)-yang bernaung di bawahnya, bekerjasama dengan asosiasi-asosiasi ilmuwan maupun profesi hukum, beserta seluruh anggotanya, dapat berfungsi memfasilitasi aplikasi yurisprudensi terapeutik dalam proses-proses hukum di Indonesia.

\section{Daftar Pustaka}


Arrigo, B. (2004). The ethics of therapeutic jurisprudence: A critical and theoretical inquiry of law, psychology and crime. Psychiatry, Psychology and Law, Vol. 11, No 2, 23-43.

Asosiasi Psikologi Forensik Indonesia. (2008). Psikologi forensik. Diakses September 10, 2008, dari http://himpsijaya.org/2008/05/15/psikologi-forensik/

Baju Khusus Koruptor Pas untuk Shock Therapy. August 7, 2001. DetikNews DetikCom. http://www.detiknews.com/read/2008/08/07/150355/984656/10/pengamat-baju-khususkoruptor-pas-untuk-shock-therapy

Brown, A. (2001, September 15). Drug courts help keep families together, Florida Bar News, p.1

Daicoff, S., \& Wexler, D.B. (2003). Dalam Weiner, I.B. (Ed.). Handbook of psychology (pp. 561580). New Jersey: John Wiley \& Sons.

de Veen, S.L.V., \& Wexler, D.B. (2006, June). Therapeutic jurisprudence sentencing principles in a Canadian context. Paper yang dipresentasikan pada The $3^{\text {rd }}$ International Conference on Therapeutic Jurisprudence, Perth, Western Australia.

Delaney, S. (2003). An optimally rights recognising Mental Health Review Tribunal: What can be learned from Australian jurisdictions? Psychiatry, Psychology and Law, Vol. 10, No. 1, 71-84.

Disefeld, K., \& McKenna, B. (2006, June). The unintended impact of the therapeutic intentions of the New Zealand Mental Health Review Tribunal? Therapeutic jurisprudence perspectives. Paper yang dipresentasikan pada The $3^{\text {rd }}$ International Conference on Therapeutic Jurisprudence, Perth, Western Australia.

Du Fresne, S. (2003) Therapeutic potential in review of involuntary detention. Dalam K. Diesfeld \& I. Freckelton (Eds.). Involuntary detention and therapeutic jurisprudence: International perspectives on civil commitment (pp. 203-220). Aldershot: Ashgate.

Eastman, N., \& Peay, J. (Eds.). (1999). Law without enforcement: Integrating mental health and justice. Oxford: Hart Publishing.

Ferencz, N. (2003). Patients' views of the Mental Health Review Tribunal in England. Dalam K. Diesfeld and I. Freckelton (Eds.) (pp. 241-262). Involuntary Detention and Therapeutic Jurisprudence: International Perspectives on Civil Commitment. Aldershot: Ashgate.

Ferencz, N., \& J. McGuire. (2000). Mental health review tribunals in the UK: Applying a therapeutic jurisprudence perspective. Court Review: The Journal of the American Judges Association, 37(1): 48-52.

Goldberg, D., \& Dimond, C. (2005). Can adolescent court reports be used to facilitate therapeutic change? Clinical Child Psychology and Psychiatry, 10, 575.

Hora, P. (2002) A dozen ears of drug treatment courts: Uncovering our theoretical foundations and the construction of the mainstream paradigm. Dalam L.Harrison, F.Scapitti, F.Amir \& S.Eintein (Eds.). Drug courts: Current issues and future perspective. Washington: Office of International Criminal Justice Publications.

Hora, P., Schma, W., and Rosenthal, J. (1999) Therapeutic jurisprudence and the drug treatment court movement: Revolutionizing the criminal justice system's response to drug abuse and crime in America. Notre Dame Law Review. Vol. 74, p. 439-538.

Hunter, R. (2002). Through the looking glass: Clients' perceptions and experiences of family law litigation. 16 AJFL 7.

Jurisprudence. (2008). In Merriam-Webster Online Dictionary. Diakses September 10, 2008, dari http://www.merriam-webster.com/dictionary/jurisprudence

Kenny, D. (1994). The relationship between workers' compensation and occupational rehabilitation: An historical perspective. Journal of Occupational Health and Safety, 10(2), 157.

Kondo, L. (2000) Advocacy of the establishment of mental health specialty courts in the provision of therapeutic justice for mentally ill offenders. Seattle University Law Review, Vol. 24, No. 2, p. 373. 
Meliala, A. (2008). Kontribusi psikologi dalam dunia peradilan: Di mana dan mau ke mana. Indonesian Journal of Legal and Forensic Sciences, Vol. 1, No. 1, 56-59.

Merry, S. E., \& Silbey, S.S. (1984). What do plaintiffs want? Re-examining the concept of dispute. The Justice System Journal, 9(2), 151-178.

Merry, S.E. (1984). Anthropology and the study of alternative dispute resolution. Journal of Legal Education, 34, 277-283.

Mnookin, R.H., \& Kornhauser, L. (1979). Bargaining in the shadow of the law. The Yale Law Journal, 88, 950.

Murfett, N.J. (2006, June). The case for a paradigm shift in civil and commercial dispute resolution - moving from fear to love: A solicitor's perspective. Paper yang dipresentasikan pada The $3^{\text {rd }}$ International Conference on Therapeutic Jurisprudence, Perth, Western Australia.

Nolan, J. (1998) Justifying government at century's end. New York University Press: New York.

Nolan, J. (2000). Therapeutic adjudication. Society, January/February, 29-38.

O'Barr, W.M., \& Conley, J.M. (1988). Lay expectations of the civil justice system. Law and Society Review, 22(1), 137.

Peachey, P. (1989). What people want from mediation. Dalam K. Kressel \& D.G. Pruitt (Eds.). Mediation research: The process and effectiveness of third-party intervention, pp. 300-321.

Petrila, J. (1996). Paternalism and the unrealized promise of Essays in Therapeutic Jurisprudence. Dalam D. Wexler and B. Winick (Eds). Law in a therapeutic key: Developments in therapeutic jurisprudence. Durham, NC: Carolina Academic Press.

Poerwandari, E.K.(2006). Kesaksian ahli dan peran psikologi dalam proses hukum: Tantangan bagi psikologi dalam kerjasama multidisiplin. Paper yang dipresentasikan pada Temu Ilmih Magister Psikologi Universitas Katholik Atma Jaya.

Probowati, Y. (2008). Peran psikolog dalam investigasi. Indonesian Journal of Legal and Forensic Sciences, Vol. 1, No. 1, 26-32

Seuffert, N (1996). Locating lawyering: Power, dialogue and narrative. Sydney Law Review, 18(503), 523

Slate, R. (2003) From the jailhouse to capitol hill: Impacting mental health court legislation and defining what constitutes a mental health court. Crime and Delinquency. Vol. 49, No. 1, p. 6.

Slobogin, C.(1995).Therapeutic jurisprudence: Five dilemmas to ponder. Psychology, Public Policy, and Law, 1,193 .219. (Reprinted in Law in a therapeutic key, pp.763 .793 by D.B. Wexler B.J.Winick, Eds., 1996, Durham, NC: Carolina Academic Press).

Soeroso, R. (1996). Pengantar ilmu hukum. Jakarta: Sinar Grafika.

Steadman, H., Redlich, A., Griffin, P., Petrila, J., and Monahan, J. (2005) From referral to disposition: Case processing in seven mental health courts. Behavioral Sciences and the Law. Vol. 23, p. 215-226.

Thornton, M. (1993). Mediation policy \& the state. Australian Dispute Resolution Journal, 230.

Trupin, E. and Richards, H. (2003) Seattle's mental health courts: Early indicators of effectiveness. International Journal of Law and Psychiatry. Vol 26, No. 1, p. 33-53.

Tyler, T. (1996). The psychological consequences of judicial procedures: Implications for civil commitment hearings. Dalam D.B. Wexler \& B.J. Winick (Eds.). Law in a therapeutic key. Durham, NC: Carolina Academic Press.

University of Arizona (2007, September 25). Legal Proceedings Can Be Therapeutic, Study Finds. ScienceDaily. Diakses September 10, 2008, dari http://www.sciencedaily.com /releases/2007/09/070920122232.htm

Wall, J.A., \& Lynn, A. (1993). Mediation: A current review. Journal of Conflict Resolution, 37, 160.

Warren, R. (2002). Public trust and procedural justice. Court Review 12. 
Watson, G., Bogart, W., Hutchinson, A., Mosher, J., \& Roach, K. (1991). Dispute resolution and the civil litigation process. Toronto: Emond Montgomery Publications Ltd.

Weisz, V., Lott, R.C., Thai, N.D. (2002) A teen court evaluation with a therapeutic jurisprudence perspective. Behavioral Sciences and the Law. Vol. 20, p 381-392.

Wexler, D. (Ed) (1990) Therapeutic jurisprudence: The law as a therapeutic agent. Durham, NC: Carolina Academic Press.

Wexler, D., \& Winick, B. (Eds.). (1996). Law in a therapeutic key: Developments in therapeutic jurisprudence. Durham, NC: Carolina Academic Press.

Wexler, D., \& Winick, B. (1991). Essays in therapeutic jurisprudence. Durham, NC: Carolina Academic Press.

White, J.J. (1984).The pros and cons of "getting to yes" essay review. Journal of Legal Education, 34, 115.

Winick, B. (2003) A therapeutic jurisprudence model for civil commitment. Dalam K. Diesfeld \& I. Freckelton (Eds.) Involuntary detention and therapeutic jurisprudence: International perspectives on civil commitment (pp. 23-54). Aldershot: Ashgate.

Winick, B. (2005) Civil commitment: A therapeutic jurisprudence model. Durham, NC: Carolina Academic Press.

Winick, B.J. (1991). Competency to consent to treatment: The distinction between assent and objection. Dalam D.B. Wexler \& B.J. Winick (Eds.). Essays in therapeutic jurisprudence (pp 59-60). Durham, NC: Carolina Academic Press. 